\title{
Los adolescentes ante las posibilidades de Internet y los nuevos medios de comunicación
}

\author{
Antonio Luque de la Rosa ${ }^{a}$ \\ Rebut: 10/06/2012 Acceptat: 14/06/2012
}

\section{Resumen}

La aparición de las Nuevas Tecnologías, a finales del siglo XX ha ido provocando, de manera paulatina, la denominada Revolución Digital, la cual ha significado un conjunto de cambios y transformaciones que han desembocado en la Sociedad de la Información, en cuyo seno las Tecnologías de la Información y la Comunicación (TIC) están suponiendo una de las causas desencadenantes de la reestructuración económica y social que se está produciendo a comienzos del siglo XXI (Área, 1996).

El proyecto que aquí presentamos pretende analizar y comprender los contextos extra-escolares como escenarios socio-educativos de uso del ordenador e internet por parte de los adolescentes y jóvenes. Este proyecto continúa recientes investigaciones en dicha temática como las realizadas por Howard (1998), Gauntlett (2000), Harrison y Lewin (2001), Hutcby y Moran (2001), Taylor y Hogenbrirk (2001) o Holloway y Valentine (2003).

Nuestra pretensión se orienta al estudio y profundización en dichos escenarios analizando, entre otros aspectos, el uso que se hace de internet, el papel que juegan en el desarrollo social y educativo de los jóvenes, las necesidades a las que responden, los problemas que plantean y las interacciones que propician. De esta manera, pretendemos elaborar un estudio de uno de estos centros de ocio educativo en una localidad almeriense profundizando en el caso de una alumna.

Palabras clave: internet; educación digital; guadalinfo; alfabetización tecnológica.

\footnotetext{
a Departamento de Didáctica y Organización Escolar. Universidad de Almería
} 


\section{Teenagers faced with the possibilities of Internet and the new media}

\section{Abstract}

The appearance of the New Technologies, at the end of the 20th century it has been provoking, in a gradual way, the Digital Revolution called, which has meant a set of changes and transformations that have ended in the Company of the Information, in whose bosom the Technologies of the Information and the Communication (TIC) suppose one of the trigger reasons of the economic and social restructuring that is taking place at the beginning of the 21st century (Area, 1996).

The project that here we sense beforehand partner tries to analyze and to understand the out-of-school contexts as educational scenes of use of the computer and internet on the part of the teenagers and young women. This project continues recent investigations in the above mentioned subject matter as the realized ones for Howard (1998), Gauntlett (2000), Harrison and Lewin (2001), Hutcby and There dwell (2001), Taylor and Hogenbrirk (2001) or Holloway and Valentine (2003).

Our pretension is orientated to the study and deepening in the above mentioned scenes analyzing, between other aspects, the use that is done of internet, the paper that they play in the social and educational development of the young persons, the needs those who answer, the problems that they raise and the interactions that they propitiate. Hereby, we try to elaborate a study of one of these centers of educational leisure in a locality almeriense penetrating in case of a pupil.

Keywords: internet; digital education; guadalinfo; technological literacy

\section{Introducción}

Las tecnologías de la información y la comunicación constituyen un referente de las escuelas de calidad (Levin, 2000). La interactividad y la virtualidad son dos características básicas relacionadas con la comunicación, la cooperación y la individualización (Martínez, 2004). Éstas podrían promover un cambio significativo en el proceso y los resultados de la enseñanza (Elboj, Valls, y Fort, 2000). El profesor puede orientar, prevenir y valorar el proceso, atender a las necesidades de cada alumno de forma gradual o crear entornos que ayudan a aprender a individuos con distintas necesidades (Bibeau, 1998; Cummis, 1989; Papert, 1995; Vigo, 2004). El alumno puede ser un protagonista activo, que toma decisiones y puede diseñar su propio itinerario. Además, las tecnologías de la información y la comunicación posibilitan la colaboración, el intercambio y la reflexión conjunta entre profesores, generándose redes en la enseñanza facilitadoras de "cambios que afectan a los entornos de aprendizaje, a la organización escolar, al currículo, a la formación del profesorado, a los roles docentes y discentes y a los métodos de enseñanza" (Martínez y Solano, 2003, p. 48). 
Desde esta perspectiva, las tecnologías de la información y la comunicación permiten pensar qué se puede hacer para contribuir a la mejora de los procesos de enseñanza (Cabero, 1998). En este sentido, podemos apreciar que dichos medios están siendo cada vez fruto de mayores aplicaciones, siendo sus funciones y características muy diversas (Claro, 2010).

Así, el uso de las TIC y las plataformas virtuales de aprendizaje pueden llegar a ser herramientas muy efectivas para todos los niveles educativos, contribuyendo a mejorar el rendimiento escolar, a fomentar la interacción entre el alumnado y a despertar el interés y motivación por el aprendizaje de manera atractiva (Guardia y Sangrá, 2005).

Son numerosas las investigaciones realizadas sobre el empleo de los nuevos medios de comunicación por parte de los jóvenes, manifiestando una constante preocupación sobre la posible incidencia que el empleo de este medio tiene en su proceso formativo (Buckingham, 1998; Buckingham y Sefton-Green, 1999; Livingstone, 2001). Estos estudios contribuyen a la información sobre el porcentaje de empleo de este nuevo medio educativo en relación con los antiguos (Livingstone 1998), analizando la forma de proteger a las personas jóvenes de la violencia presente en internet y los juegos de ordenador (Magrid, 1998; Oswell, 1999) y explicando cómo la escuela puede usar las nuevas tecnologías para ayudar a profesores y alumnos en el proceso educativo (Albero, 2001; Buckingham, 1998). En caso del empleo de internet por parte de los niños y adolescentes es también evidente una tendencia a ver esta tecnología como un instrumento necesario para el desarrollo de las capacidades de razonamiento, creatividad y comunicación (Castells, 2001; Tapscott, 1998).

Otro tipo de estudios intentan profundizar en los efectos en el alumnado en relación con las destrezas y procesos educativos y socioafectivos (Cox, 2003; Cox y Marshall, 2007). No obstante estos estudios son aún poco consistentes y muchas veces contradictorios.

En este sentido, si bien hay señales de efectos del uso de TIC en los aprendizajes, ello no está necesariamente vinculado al simple acceso o a un determinado uso -más o menos intensivo- de estos medios (ya que en algunos casos puede incluso estar asociado a peores resultados) sino al tipo de uso de dichas tecnologías y la combinación de una serie de factores consustanciales que resulten propicios (Adell, 2003; 2004).

Para dichos estudios, el problema sería esclarecer de forma consistente cuáles son esos tipos de uso o las razones detrás de la relación positiva o negativa entre ciertos tipos de uso y resultados de aprendizaje, volviéndose realmente difícil distinguir el impacto que una intervención específica genera en el alumno (Balanksat, Blamire y Kefala, 2006; Condie y Munro, 2007). De esta manera, no parece fácil determinar el papel que puede desempeñar dichos medios en cada uno de los aspectos educativos y los usos incidentes de carácter comunitario que habría que desarrollar para acentuar su vertiente positiva, 
Ante dicha situación surgen interrogantes sobre si las TIC se están incorporando en los centros solamente desde un punto de vista tecnológico o se está realmente incardinando su vertiente pedagógica y en qué medida. Al mismo tiempo surgen demandas de valoración de la eficacia de las TIC para la mejora de la calidad de la enseñanza cuestionando el sentido de las mismas y la utilidad que están significando en la realidad (Dias, 1999; Dodge, 2002). Estas cuestiones, y otras muchas, demandan una reflexión profunda con objeto de conocer dónde nos encontramos y hacia dónde nos dirigimos en el desarrollo de la educación tecnológica (Downes, 2004; Etcheverry, 2005).

El caudal de datos, investigaciones e informes sobre la 'implantación' de las TIC y especialmente de internet en las escuelas (o en ambientes-contextos educativos formales), resulta ser un hecho irrebatible; sin embargo, sorprende comparativamente el escaso conocimiento disponible sobre la interacción de los menores y adolescentes fuera de la escuela, sus estrategias de uso y de aprendizaje, el papel que juegan estos escenarios de uso y los agentes en ellos, las prácticas que desarrollan y las habilidades que adquieren, la forma de adquisición y las características básicas de la así denominada- nueva 'tecno-cultura' (de adolescentes y jóvenes).

En este sentido, "Guadalinfo" surge como parte del "Plan Estratégico para el Desarrollo de la Sociedad de la Información en Andalucía". Dicho proyecto Guadalinfo, tiene como objetivo principal, la Alfabetización Digital de aquellas generaciones y sectores que no conocen ni la utilidad, ni el funcionamiento de las nuevas tecnologías, tratando de evitar en todo momento, la conocida "brecha digital".

Los centros Guadalinfo son espacios públicos, de libre acceso dotados de equipamiento informático y conexión a internet en banda ancha, a través de los cuales se conseguirán alcanzar el objetivo principal del proyecto, estando destinados a todos los ciudadanos y ciudadanas de localidades de menos de 10.000 habitantes, aunque solidariamente, los primeros en beneficiarse del proyecto deberán ser aquellas personas y organizaciones con mayores dificultades de acceso a las nuevas tecnologías, siendo considerable la atención que se viene mostrando hacia el colectivo de adolescentes y la incidencia que puede representar de cara a la adecuada educación digital.

Nuestra pretensión se orienta al estudio de uno de dichos escenarios, analizando su carácter social y educativo, el uso que se hace de internet, el papel que juega en la comunidad, las necesidades a las que responde, los problemas que plantea y las interacciones que propicia. De esta manera, pretendemos elaborar una imagen comparativa del uso y del acceso de los ordenadores e internet que llevan a cabo los adolescentes y los jóvenes. Con ello se pretende generar un conocimiento que permita a los educadores comprender los nuevos patrones de relación con la información y socialización de los jóvenes aplicable a la enseñanza y a la formación del profesorado. 


\section{Diseño de la investigación}

El objetivo general del estudio se encuentra en comprender el acceso y uso de internet de jóvenes, así como las interacciones y prácticas que despliegan, desarrollan y generan en este tipo de escenario socio-educativo ${ }^{1}$. Ello implica asumir la importancia de una doble problemática.

a Primero, que las interacciones de los agentes y sus prácticas, en relación con el uso de internet, son un elemento clave para comprender en profundidad el desarrollo, la implantación y penetración social y educativa de dicho medio. Por ello, en lugar de sobre-estimar el valor del 'contenido' en internet o de la 'comunicación on-line'; esta investigación pretende enfatizar, por así decir, lo que ocurre alrededor de la pantalla y del ordenador conectado ${ }^{2}$ : es decir, el contexto social del uso de internet

b Segundo, que existen contextos socio-educativos paralelos y complementarios al contexto 'educativo' tradicional de uso de dicha tecnología: la escuela. Uno de estos contextos son los centros de ocio educacional como el que aquí analizamos. Es imprescindible, como ya han sabido ver algunos investigadores anglosajones, el papel que juegan en el acceso a las TIC, para poder mejorar considerablemente, los procesos educativos con y de las TIC en las escuelas.

Nuestra pretensión en el informe que presentamos está orientada a la consecución de los siguientes objetivos:

a Comprender el escenario social y educativo formado por un centro "Guadalinfo", analizando, entre otros aspectos, el empleo de internet por parte del alumnado, las necesidades a las que responde, los problemas que produce y las interacciones que esto propicia.

b Elaborar una imagen comparativa del empleo y del acceso a los ordenadores e internet que los adolescentes realizan.

c Generar un conocimiento que permita a los educadores entender los nuevos principios y criterios relacionados con el mundo digital y la socialización de las personas jóvenes y su aplicación al ámbito educativo y a la formación del profesorado.

La investigación que ahora se presenta se incardina en un enfoque o paradigma interpretativo, y ello por la naturaleza del hecho investigado, por los propios fines de la actividad investigadora, por el modo de abordar el análisis e interpretación de los datos y por la metodología cualitativa de la que nos servimos para la toma de información, siendo predominante en este tipo de investigaciones sociales y educativas. 
De esta manera, en investigaciones como la presente, las entrevistas etnográficas (formales e informales) y los estudios de casos, se han convertido en los últimos años en procedimientos metodológicos fundamentales (Livingstone y Bovill, 1999; Stake 1995; Vázquez y Angulo, 2003).

Son numerosos los autores que consideran los estudios de casos o análisis de realidades concretas como el método más idóneo que permite el conocimiento de lo idiosincrásico, lo particular y lo único, frente a lo común, lo general y lo uniforme, por cuanto presta atención a lo que específicamente puede ser aprendido de un caso simple, de un ejemplo en acción (Stake 1995). No obstante, al mismo tiempo, ofrece la posibilidad de ir más allá de la experiencia descrita, puesto que al documentar la especificidad conecta con la experiencia de la audiencia a la que va dirigida el informe (Walker 1989). Así, según Stake (1995), el objetivo de toda investigación cualitativa consiste en acercarnos a la comprensión de las complejas interrelaciones que se dan en la realidad, centrando la indagación en los hechos.

Por todo esto, consideramos que sólo desde esta perspectiva podemos acercarnos al conocimiento de la realidad educativa que pretende analizar esta investigación (Goetz y LeCompte, 1988; Rodríguez, Gil y García, 1996; Taylor y Bogdan, 1986) puesto que la misma es cambiante y el contexto social y los individuos que la conforman, la influyen y determinan.

\section{Identificación del caso-Guadalinfo:}

En Andalucía la Consejería de Innovación, Empresa y Ciencia, viene realizando una política de extensión de la sociedad de la información y el conocimiento, en paralelo a la política desarrollada por la Consejería de Educación y de los municipios.

Dicha política se ha orientado a la creación de los así denominados Centros Guadalinex y en su promoción, no sólo como puntos de acceso a internet, sino de alfabetización digital. Dichos centros están abiertos tanto a adultos como a menores, adolescentes y jóvenes en general.

El centro objeto de esta investigación se encuentra ubicado en Albox, localidad de 10.000 habitantes del norte de Almería.

\section{Técnicas e instrumentos:}

Se han mantenido entrevistas con diez alumnos de 12/13 años (Alumnos) así como con el dinamizador-coordinador del centro (Dinamizador), profundizando en el caso de una alumna (Alumna en profundización) y su contexto familiar (Madre). Se ha procedido igualmente al análisis de documentos, fotos y observaciones/conversaciones informales (recogida de datos en cuadernos de campo. 


\section{Informe de investigación Descripción del servicio del centro}

En este centro existe un servidor que marca la jerarquía de red junto a catorce ordenadores clientes que no tienen información alguna; sin estar encendido el servidor dichos ordenadores no hacen nada. Según el dinamizador, a esto se denomina red "en estrella".

El sistema operativo que se utiliza es el Guadalinex (de Linux), recopilado por la Junta de Andalucía. Empezó por la versión normal y ya va por Guadalinex V.4. Es más avanzada, el entorno gráfico es más agradable. Se parece al Windows pero es de código abierto y no se cobra por las aplicaciones del mismo. Nos comenta el dinamizador que se puede cobrar por las mejoras de ese código pero no por el código base.

El servidor tiene dos discos duros, uno de copia de seguridad y otro de funcionamiento. Cada uno tiene $160 \mathrm{~Gb}$. A cada usuario le administra una capacidad. Cuando se registra por primera vez se le asignan $50 \mathrm{Mb}$, aumentándolas en función de sus necesidades. Han llegado a tener algunos $4 \mathrm{~Gb}$, pero, según nos comenta el dinamizador, esto se hace hasta donde se puede porque en dicho centro hay actualmente cerca de mil quinientos usuarios.

"No podemos darle a todo el mundo un Gb" (Dinamizador).

Según nos comenta el dinamizador, la política que se sigue en este centro es no privatizar el almacenamiento, es decir, no dar a un usuario $4 \mathrm{~Gb}$. Se les puede dar en un momento dado porque lo necesite pero luego debe recuperar esa información y dejar ese espacio para otra gente que lo necesite.

Hay grabadora de Dvd en el servidor, todos los ordenadores tienen lector de Dvd. Como la información está en el servidor, desde los clientes no pueden grabar ya que además no tienen privilegios para ello.

Desde el año 2008 tienen sistema Wifi y un punto de acceso de manera que los portátiles también puedan navegar, siempre y cuando se pida autorización y contraseña, respetando unos filtros que hay, ya que este centro trabaja con una red de diputación (intranet de diputación) y ella los tiene, para seguridad.

Los ordenadores no poseen sistema bluetooth; scanner sí pero de carácter básico, con una resolución de 1600 x 1200; impresora a color Hp y dos impresoras láser. Cada monitor lleva sus altavoces y el dinamizador ha completado con unos externos que son suyos, "ya que se han hecho actividades como videoconsolas, algo de música, cursos, etc., y hacían falta para que se pudiera escuchar bien" (Dinamizador).

Todos los monitores son TFT de 15 pulgadas y la conexión a internet en todos los ordenadores es por cable. Todo se conecta en estrella al servidor, el cual posee un router que es el que se conecta a internet. 
También nos comenta que hay cámara de fotos, proyector, usb, lápiz de memoria, teléfono fijo, aire acondicionado y bomba de calor.

Este centro Guadalinfo, al tener Albox ADSL, va por telefónica, pero en los pueblos donde no llega ADSL estos centros van por Iberbanda (intenet por satélite, que depende de las condiciones climatológicas la intensidad de la señal) o frecuencia de radio o satélite.

No hace falta antivirus, con el Guadalinux hay una seguridad ya que al utilizar distintos discos duros, la información se guarda en uno y se utiliza en el otro, por lo que si entrara un virus, como se utiliza en un disco duro distinto, el virus afectaría sólo al disco duro donde están los datos. El cortafuegos es de diputación.

Es un centro que empezó a funcionar en el año 2004, manteniendo un carácter compartido con cursos de cocina organizados por el Ayuntamiento de Albox y con agentes locales de promoción de empleo (ALPES) (1).
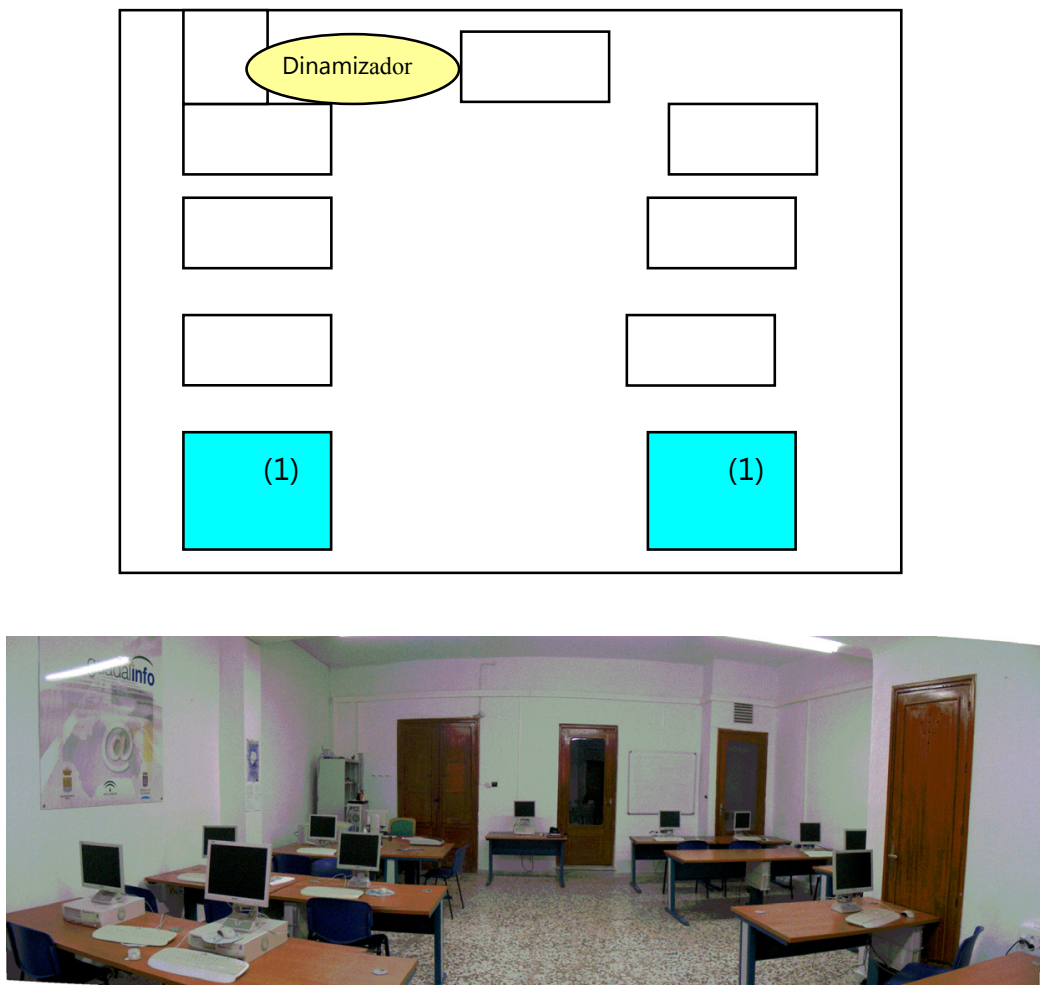

(Centro Guadalinfo Albox)

Los ordenadores están dispuestos en estrella para la protección del sistema, así los ordenadores-cliente no tienen privilegios de instalación/desinstalación ni de borrado. De esta manera se carga todo en el servidor y la gente lo que hace es consultar los 
datos. Así se controlan todos los usuarios. Según nos comenta el dinamizador, no pueden controlar lo que navegan por la ley de protección de datos pero los contenidos, se supone que el filtro de diputación los controla. Si es algo no educativo debe impedirlo, "pero sabemos que no lo hace del todo, ya que ha habido quejas por que algunos banner que saltan impiden acceder a páginas interesantes que por alguna pequeña cosa se cortan" (Dinamizador).

\section{Normas de uso y acceso}

El Centro Guadalinfo es de acceso libre y gratuito para todos los ciudadanos de Albox, debiendo realizar la correspondiente inscripción como usuario del mismo. Los datos proporcionados por los usuarios solamente se utilizarán con fines de identificación y de generación de estadísticas de uso de los recursos del Centro Guadalinfo (Reglamento de Régimen Interno).

Los horarios de disponibilidad son de 9.00 h. a 14.00 h. y de 18.00 h. a 21.00 h. de lunes a jueves.

Se intenta promover que todo usuario respete al prójimo en todo momento, guardando silencio y comportándose de manera cívica, sin estar permitido comer, fumar ni consumir bebidas de ningún tipo (Reglamento de Régimen Interno).

Se potencia el cuidado y mantenimiento limpio el Centro Guadalinfo usando las papeleras, ceniceros y otros elementos habilitados a tal efecto. Deberán custodiar los recursos utilizados en el mismo estado de limpieza y conservación en el que lo encontraron (Reglamento de Régimen Interno).

Se cuida el carácter educativo de las actuaciones que en él se desarrollan, vigilando el correcto uso de los accesos a internet por parte de los usuarios:

"Aquí nos ponen límites, no más de 1,30 h de navegación y hay páginas que no nos dejan navegar, pero no saben por qué. Les sale un filtro que los prohibe. Si son páginas de lucha no deja" (Dinamizador).

\section{Ámbito social, acción y coordinación}

Según nos comenta el dinamizador, la iniciativa del proyecto es cubrir la brecha digital para aquellos que no tengan acceso en su casa. Al ser Albox un pueblo grande no es por socializar (como en un pueblo pequeño donde estos centros se convierte en centros sociales), sino que se utiliza más como ayuda a los desfavorecidos, pero se le deja a todo el que quiera, y se responde a todas sus demandas (mayores, jóvenes, etc.).

"Surgió como consecuencia de la alfabetización digital para cubrir la brecha digital y para los pequeños que se apuntaron al carro de las nuevas tecnologías" (Dinamizador). 
Así, se garantizó que en esta localidad, al igual que en el conjunto de Andalucía, hubiese un centro en el que se pudiera tener acceso a internet por parte del conjunto de la población, favoreciendo la alfabetización digital mediante distintas actividades y horario en función del tipo de población atendida.

No obstante, el objetivo del proyecto ha cambiado en los últimos años, pasando ahora a centrarse más en la educación del uso responsable de las nuevas tecnologías, al considerar que la gran mayoría de los ciudadanos tiene, de una u otra forma, acceso a internet.

\footnotetext{
"Ahora el objetivo del proyecto supone que esas fases se han superado y ahora la siguiente fase es el uso responsable, ya saben que hay que tener un poco de responsabilidad" (Dinamizador).
}

Así, es conveniente advertir sobre los peligros y consecuencias de las descargas fraudulentas, los virus, el uso moderado y consciente de las redes sociales, etc.

"Ellos no son conscientes de si está bien hecho o no, sin tener en cuenta si el ordenador ha tenido un virus y mi padre ha tenido que formatearlo y que le ha costado 60 euros, ellos al final no lo aprecian, lo único que aprecian es que se han descargado un juego y que lo tienen y juegan" (Dinamizador).

Es necesario ese proceso formativo para explicar los peligros de un mal uso de internet y hacerlo desde edades tempranas.

"Si pero los peligros de la informática hay que explicarlos desde primera hora, porque un chiquillo que ya ha recorrido muchos caminos cómo le explicas ahora que hay mucha inseguridad" (Dinamizador).

Por otra parte, sería fundamental la colaboración de las familias para dicho aspecto educativo de las buenas prácticas en internet, ya que es en sus casas donde realmente pasan la mayor parte del tiempo conectados.

"Dicen vamos a las buenas prácticas al Guadalinfo, pero si luego en su casa van a hacer lo que les dé la gana, qué buenas prácticas les podemos dar así. Es lo que está pasando" (Dinamizador).

Así, los padres suelen desconocer lo que sus hijos hacen en el Guadalinfo y carecen de conocimiento informático para realizar un adecuado seguimiento y orientaciónapoyo de las tareas de sus hijos.

"No sé lo que hace en el centro y mi hija no me habla de lo que hace allí" (Madre).

"Yo no tengo información para saber educar a mi hija en internet, aunque creo que sería necesario y que tendría que saber manejar las herramientas..." (Madre)

De esta manera, el problema es el desconocimiento de los padres y que no le dan importancia que tiene el tema al creer que con un ordenador no pueden llegar a hacer cosas malas.

"Los padres no se dan cuenta del peligro de las redes sociales, no saben del peligro por desconocimiento, por su trabajo no utilizan y no han tenido ordenador y creen 
que el ordenador es un juego, no una herramienta para que les ayude en el colegio, no lo ven como una herramienta" (Dinamizador).

Ante el tema de la seguridad y el uso responsable, se han desarrollado numerosos cursos desde el centro Guadalinfo, intentando captar tanto al alumnado como a los padres para asegurar el beneficio de las acciones que comentamos. En cualquier caso, a dichos cursos suelen asistir, en su mayoría, gente adulta que buscan la formación en aspectos puntuales como medio de apertura social.

"Para el tema de las redes sociales se realizan cursos formativos, si bien son las personas mayores los que realizan más demandas de asistencia a los mismos. Los jóvenes no van a los cursos, van más que nada a utilizar internet, los cursos van más dirigidos a gente mayor" (Dinamizador).

Así, entre la gente que utiliza la navegación libre -mayoritariamente niños entre los 10-16 años-, el dinamizador los intenta agrupar por inquietudes o por edades. Cuando hay un grupo en espera de una actividad de formación (un mínimo de 5) se hace un curso para ellos que responda a sus necesidades, aunque luego se completa con otros usuarios que se interesen, y se discute el horario que les convenga

Además, en los casos en que dichos cursos son realizados por jóvenes, se echa en falta la necesaria coordinación con las familias, ya que sólo podremos garantizar una aplicación real de lo impartido si contamos con el apoyo y mantenimiento de las mismas reglas y normas en el ambiente familiar.

"Hay cursos, ellos hacen cola para meterse y se les explica las buenas prácticas, los riegos que tienen las redes sociales, etc., pero cuando se van a su casa no se les puede controlar los móviles, internet..." (Dinamizador).

Por otra parte, los jóvenes, sobre todo al llegar al instituto, dejan de mostrar interés por dichos cursos, siendo partidarios de utilizar internet como medio de ocio y de comunicación social (redes sociales) y descuidando las reglas de su uso o la inversión de tiempo en el aprendizaje de su útil aprovechamiento.

"En cuanto llegan al instituto vienen al Guadalinfo y no les interesan ningún curso, los chiquillos lo que quieren ahora, sobre todo esa generación de los 12 años a los 16, es estar pendientes sólo de las redes sociales" (Dinamizador).

Además suelen reducir su tiempo de asistencia al centro Guadalinfo y cuando vienen se centran en un uso práctico y reducido de la navegación (descargas o redes sociales), perdiendo interés por la formación o por el uso responsable.

"Pues suelen ir la gente mayor y los zagalillos pequeños. Yo voy menos y hago las cosas en mi casa. Me acerco a consultar las redes o para descargarme música" (Alumna profundización)

"Yo en Albox llevo desde el 2007 al 2010. He tenido varias generaciones, pues los que en el 2007 estaban en $5^{\circ}$ ó $6^{\circ}$ cuando llegan al instituto vienen menos por aquí, también porque tienen que estudiar más, pero no vienen para aprovechar el tiempo, van a conectarse 5 minutos al tuenti" (Dinamizador). 
Al dedicar tanto tiempo a las redes sociales, los trabajos escolares se vuelven "basura", aprovechando los trucos de internet y "copiar y pegar" para agilizar los mismos.

"Sí, le dedican muchísimo tiempo; entonces no me vale que luego me vengan con historias. Eso que se lo digan a otro todavía, pero yo los veo, porque las redes sociales te sirven pero por otro lado te pueden tener controlado todo lo demás, por eso cuando yo les digo que se descarguen información se meten en la wikipedia. Esto lo han aprendido de memoria y cogen y seleccionan desde arriba hasta abajo y algunos cogen hasta el anagrama" (Dinamizador).

Cuando el alumnado ya ha pasado de los 16 años suele estar más seguro de lo que quiere y se dedica a hacer bien su trabajo, siendo el periodo 12-16 el más problemático de cara a la orientación del uso responsable de internet.

"El que ha pasado de los 16 está seguro de lo que quiere: hacer bien para su trabajo y su estudio. En el paréntesis 12-16 sólo están pensado en hablar con éste con la otra, en lo que han puesto en el tuenti o en facebook. Yo no entiendo cómo todavía no se ha mediado desde los sitios educativos. Hay que darles una educación, si no esta generación está perdida en lo que se refiere a la informática" (Dinamizador).

Quiero señalar que, de los alumnos entrevistados en este estudio, dos están en $6^{\circ}$ de primaria. Tienen 2 y 4 hermanos mayores respectivamente (ellos son los más pequeños). Sus padres trabajan como montador de chimeneas y soldador de máquinas, dedicándose las madres a las tareas domésticas.

En cambio, la alumna de profundización es mayor. Está en $3^{\circ}$ ESO. Tiene un hermano de 20 años y es huérfana de padre. Su madre trabaja como administrativa en el Ayuntamiento. Según nos comentan, se suelen poner de uno en uno en los ordenadores ya que hay muchos. No se ha hecho aún ninguna actividad de dos en dos.

"Venimos solos y aquí hacemos amigos". (Alumnos)

Cuando vienen solos también se ponen de uno en uno (trabajos, correos, consultas...) ya que se intenta respetar la información privada. Además cada uno entra con su contraseña y entra como único usuario. Con la política de privacidad cada cual guarda sus documentos y nadie debe verlo. Si algún usuario quiere que alguien se ponga al lado eso es su voluntad. El dinamizador nos comenta que, si quieren, les deja de dos en dos.

"Venimos cuando tenemos que hacer algún trabajo o algo, nos metemos en internet de uno en uno". (Alumnos)

Otra faceta de coordinación que habría que considerar es la realizada con los profesores de los centros educativos, los cuales deberían realizar acciones formativas con el alumnado y no sólo dar por sentada la formación en la materia para su utilización meramente instrumental, lo cual acaba provocando un uso viciado y fraudulento en torno a los trabajos que desde los centros se plantean. 
"Dicho proceso formativo debería realizarse desde primera hora y en colaboración con padres y profesores, con objeto de garantizar su eficacia, si bien no es algo que se vea de manera generalizada" (Dinamizador).

Incluso en la faceta meramente instrumental, tampoco está garantizado que el conjunto de los alumnos tenga ordenador en casa y que domine en mecanografiado, manejo del software-procesador o navegación por la red.

"Así, muchos chiquillos, con los trabajos que les exigen los profesores, que sean en el ordenador, si no hay ninguna asignatura de informática en el colegio cómo les exigen a un niño que el trabajo sea en el ordenador. Incluso si tienen ordenadores en casa, pero yo también puedo tener un pico y no saber" (Dinamizador).

Como conclusión de todo lo que venimos comentando, podemos destacar el gran desfase que existe entre los tres sectores sociales que comentamos en relación con el uso de las tecnologías digitales: jóvenes, docentes y familiares

"Hay una brecha digital entres los tres increíble en las nuevas tecnologías: los alumnos porque el $80 \%$ saben más que los profesores; los padres, por lo menos el $40 \%$ son totalmente nulos. Entonces si no hay un seguimiento desde el colegio, el alumno va por delante del profesor y los padres no tienen ningún manual para saber lo que está bien o no; es totalmente incontrolable" (Dinamizador).

Contra esta realidad se han tomado algunas iniciativas en el centro Guadalinfo, como es la realización de proyectos de formación conjuntos, intentando fomentar la participación conjunta del profesorado de los colegios en sesiones formativas con los padres de cara a la utilización de las herramientas informáticas y del uso responsable de internet, pero el resultado no ha sido alentador.

"Al final del curso pasado se realizó un proyecto, las tic en las aulas, con objeto de ayudar a los padres a que sepan cómo es el ordenador para que los padres vengan al Guadalinfo con los ordenadores y explicarles cómo funciona un ordenador. Profesores de los 3 colegios vinieron y 9 miembros de las asociaciones de padres. Hablé con ellos, pero fue como hablar con la pared. Y los alumnos algunos vinieron y otros no. Pero es normal, si los profesores y los padres no presionan" (Dinamizador).

Quizá el problema no está en los familiares sino en los planteamientos que se realizadn desde las instancias para motivar su participación y formación, provocando que ese aprendizaje sea efectivo. No es normal que desde la Junta de Andalucía se haya proporcionado ordenadores al alumnado (Escuela TIC 2.0) y no se hayan instaurado los mecanismos de formación y orientación a los padres sobre su uso o seguimiento por los hijos.

"La verdad que me interesa mucho y me encantaría saber sobre el tema para ayudar a mi hija..." (Madre) 


\section{Tipología de actuaciones desarrolladas}

El centro de Albox tiene destinado, para lo que es el funcionamiento del centro, 35 horas semanales y se distribuyen en cuatro tipo de actividades

a De coordinación del centro (planificación de actividades a realizar, funcionamiento del centro, cumplimentación de datos que pide la Junta): 10 horas. Se pueden distribuir cómo se quieran siempre que no sean más de dos horas seguidas por día.

"En esas horas no tiene por qué estar abierto el centro porque no vas a estar pendiente de la gente, aunque nosotros aquí siempre lo tenemos abierto". (Dinamizador)

b Luego hay 5 horas de navegación libre para el usuario.

c Las otras 20 horas se dividen en cursos de formación o actividades formativas, actividades coordinadas con otros centros/provincias y actividades fuera de las formativas (talleres, tertulias, charlas, cuestiones que les interesen al usuario). Aquí, según nos comenta el dinamizador, se han hecho torneos de play station con los críos, talleres de pintura, exposiciones de escultura... En definitiva, cualquier actividad que interese al usuario.

Según nos comenta el dinamizador, los más pequeños utilizan los ordenadores para cosas lúdicas, juegos, vídeos de youtube, etc., aunque no se los pueden descargar. Los más jóvenes suelen navegar, utilizar el Chat, Messenger, cosas lúdicas para entretenerse.

"Tenemos muchos contactos en el Msn: 128. Se suelen meter muchos a la vez, según la hora. Hablamos con algunos, no con todos, al primero que conteste. El correo electrónico no lo vemos mucho, pero a veces sí, el Hotmail, para ver los mensajes"

(Alumnos).

Los mayores (+17 años) para hacer trabajos, para consultar datos universitarios, ver notas, etc. Nos comenta el dinamizador que en el pueblo hay mucha gente que no tiene internet y para eso está dedicado todo esto. Por eso se le permite que, si está fuera de las horas de navegación libre, consulte de cualquier forma.

"Hay gente que nos pide ayuda para sacar la vida laboral, utilizar la firma digital, etc." (Dinamizador).

Asimismo, esta gente mayor sí suele utilizar el Msn o los Chat para comunicarse con la familia. Los alumnos nos comentan que en su casa no tienen ordenador con internet, siendo ese el motivo por el que acuden al centro.

"Si tuviéramos internet no vendríamos. Yo preferiría entrar en casa porque estoy más íntimo." (Alumnos)

Uno tiene ordenador en casa (en su cuarto) y otro no. El otro amigo dice que se lo van a comprar ahora y se lo pondrán en su cuarto. Sus habitaciones tienen póster de lucha y decoración abundante. Están solos en su habitación y no la comparten. 
Según la madre entrevistada, considera que su hija acude al centro por la ayuda que le proporciona el dinamizador a la hora de realizar los trabajos de clase, ya que tiene internet en su casa y realiza mucho tiempo en la misma conectada para los contactos y comunicaciones en las redes.

"Yo pienso que va al centro porque el chico del Guadalinfo le ayuda en muchas cosas" (Madre).

\section{Códigos emergentes}

"El lenguaje que utilizan en el Msn es un castellano cambiado, se están perdiendo las reglas y cada uno utiliza las letras como él quiere, metiendo dibujitos en medio" (Dinamizador).

Según nos comenta el dinamizador, parece un jeroglífico y cada uno lo hace a su manera.

"De cualquier forma, también es ingenioso y desarrolla la imaginación pero es un código libre..." (Dinamizador)

Eso códigos se los van comunicando y cambiando de uno a otro, con la propia práctica. Nos comenta el dinamizador que la gente mayor cuando se comunican con los hijos no lo entiende y le preguntan a él. Al tiempo, ellos mismos acaban utilizando también esos códigos, por reducir el tiempo, por agilizar la conversación.

La utilidad del correo parece menor ya que, si bien en la gente mayor predomina, los jóvenes quieren una respuesta rápida, interactuar rápidamente, pregunta-respuesta. El correo electrónico les gusta menos a no ser que sea para enviar una foto. En el correo electrónico hay que exprimir más la información, ya que como se sabe que no va a tener la información inmediata pues envías todo bien completo y pensado, es como una carta y la gente joven no está acostumbrada a redactar. Ellos quieren preguntas cortas y rápidas para obtener información corta y rápida y así echar el rato. Eso está bien porque están aprendiendo una forma de comunicarse pero se está desvirtuando las normas de esa forma comunicativa; nadie les está enseñando cómo comunicarse.

"Aquí se intenta dar unas pautas a seguir pero es complicado. Yo les propongo ejercicios y trabajos donde ellos cogen información y me hacen resumen para ver la capacidad que tienen de leer y comprender. Les animo a terminar con algún premio, de jugar, etc. Así, leen, que es una cosa que antes de llegar aquí estaba perdida, ya que no leían nada, sólo jugar y Msn, cosas que no les aportaba nada nuevo. " (Dinamizador).

Nos comenta el dinamizador que la utilidad de este tipo de actividades se ve reflejada en las conversaciones del Msn ya que, sólo con la realización del resumen, comienzan a manejar mejor el ratón/teclado, escriben más rápido y en el Msn, al escribir más rápido se comen menos letras en su lenguaje individual. 
Los alumnos entrevistados nos comentan que esto de manejar el Msn o utilizar un lenguaje simplificado se aprende de costumbres de escribir, lo hemos visto a los hermanos mayores y también a mis padres y amigos. Otras veces reconocen que lo inician aquí.

Cada usuario se puede poner en el ordenador que quiera, que con su clave y usuario, disponiendo de su propio espacio con su configuración.

"Si él quiere la del Guadalinfo pues esa, si no pues puede cambiar todas las cosas que quiera en escritorio, etc. Pone la foto, iconos que quiera..." (Dinamizador)

Como apodos se ponen nombre de personajes de ficción o de dibujos animados, por ejemplo mother o raider, reconociendo que suelen estar en el centro desde las 7,30 h. hasta las $9 \mathrm{~h}$. los lunes, miércoles y jueves (como ocio recreativo). Les gusta cómo está Guadalinfo y no les hace falta el viernes que dedican al fútbol o a otra cosa.

\section{El teléfono móvil y los jóvenes}

Suelen comenzar muy pronto el uso de los móviles, existiendo una gran mayoría que lo tienen de uso común y personal.

De los alumnos entrevistados, uno tiene teléfono móvil y otro no. En casa del primero tiene un móvil cada miembro (cuatro teléfonos), existiendo un límite en el consumo asignado.

"Es tarjeta de saldo y cuando se acaba y se gasta pues ya está" (Alumnos).

En cambio, la alumna de profundización no tiene límite en el gasto.

"No, no tengo, limite en el gasto" (Alumna profundización)

Los suelen utilizar principalmente para comunicación, aunque también reconocen su utilidad para hacer fotos o escuchar música.

"Para escuchar música, hacer fotos y comunicarme con mis amigos" (Alumna profundización)

Con los móviles se comunican mediante llamadas, toques y mensajes. Los toques tienen mensajes variados: "que no nos queda saldo", también "que me acuerdo de ti", según quien lo dé significa una cosa u otra. También se mandan fotos pero advierten que es más caro y lo hacen menos. Guardan algunos de los mensajes, aunque los de publicidad no. En la portada del móvil tienen a sobrinos o familia. No tienen fundas pero sí pegatinas de luz, antes de que empiece a sonar. Como normas sus padres les dicen que no llamen por tonterías y les han dicho que no llamen a prefijos de compraventa, etc. Es curioso que no les han advertido para que no llamen a prefijos 908 ó 905 que son de adultos. Así, el único control que suelen realizar es el relacionado con el consumo.

"Lo controlo por que le miro el móvil y miro el consumo que tiene" (Madre). 
Los mensajes de móvil lo utilizan, pero "debemos controlar porque si no la factura..." (Alumnos), siendo frecuentemente emitidos hacia los contactos usuales que suelen ser amigos.

Cuando escriben los nicks (tanto en internet como en los móviles) ponen letras y hacen palabras raras (Raider) o de personajes de dibujos animados, etc. A veces salen de los propios nombres. Asimismo reconocen que les ponen fotos suyas o de internet, que los personalizan.

Como hemos comentado en el apartado anterior, es frecuente la utilización de códigos propios que van "negociando" entre grupos más o menos amplios en cuanto al significado asignado.

"Hay algunos universales, pero otras palabras que entendamos nosotros, entre amigos" (Alumna profundización)

\section{Internet, ocio y adolescencia}

Como juegos utilizan páginas on line y también lo hacen en red para comunicarse entre todos, cada uno tiene un tiempo de espera para que el otro maniobre. Pueden jugar entre ellos de aquí o entre ellos y otros de otro lugar. Son juegos de estrategia, debiendo ingeniárselas para vencer mediante herramientas.

"Jugamos a juegos de lucha, pressing-cach, fingidas. No es bonito pero me gusta como entretenimiento" (Alumnos).

De vídeojuegos tienen la play-station, y la game-boy no pirateadas. Los juegos los compran. Les gustan los de aventuras (kin-kong). Tienen lector de mp3 con pantalla, aunque no de mp4. Lo utilizan de vez en cuando. Les gusta música tecno, house, y trasvasan la música del ordenador al mp3. Aquí no pueden descargar pero sí en casa o de otros amigos. Les gustan las películas de terror, de deportes, de aventuras, de risa. De TV les gustan los concursos, series "el internado..." La radio no la utilizan, utilizan más la música en el ordenador y en el mp3.

Suelen comenzar muy pronto el uso de internet, dedicándolo a actividades variadas: comunicación y redes sociales, descarga de juegos, música, navegación libre y consulta de información, apoyo al estudio, etc.

En la faceta comunicativa (chats, foros o correos) encontramos el mismo fenómeno de los códigos emergentes, si bien en menor medida que en los sms, dado que aquí no hay límite de caracteres.

Al igual que con el uso de los móviles, no existe al adecuado control paterno en cuanto al uso que se realiza, lo cual se ve incrementado debido al desconocimiento familiar del manejo de estas herramientas y los peligros que pueden conllevar.

Sólo, en ocasiones, existe una restricción en la cantidad de tiempo que desde el ambiente familiar se considera aconsejable para estas actividades. 
Si analizamos el ambiente familiar de trabajo de uno de estos alumnos, apreciamos que en su cuarto no dispone de impresora o escáner, debiendo ir a la habitación del adulto cuando necesita tales servicios, lo cual es indicativo del uso que da al ordenador e internet y de la importancia que la familia otorga al uso responsable y productivo del mismo.

"Trabajo aquí, luego voy para imprimir a la habitación de mi madre. Tampoco suelo utilizar el escáner. Si me hace falta pues voy a ese cuarto" (Alumna profundización)
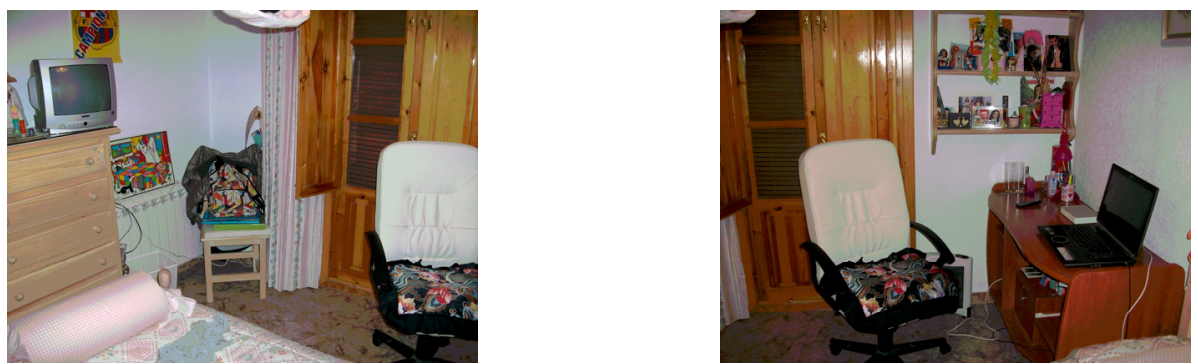

(Habitación alumna $3^{\circ}$ ESO)

Como vemos, en la habitación de esta alumna no existen estanterías con libros o material de trabajo visible, abundando los aspectos decorativos, un sillón cómodo y un portátil con conexión por cable (ADSL). Tampoco se aprecian juegos, equipos de música u otra faceta de ocio. Este hecho refrenda la principal actividad recreativa que realiza la alumna, ocupando el portátil la totalidad del espacio de trabajo en la mesa.

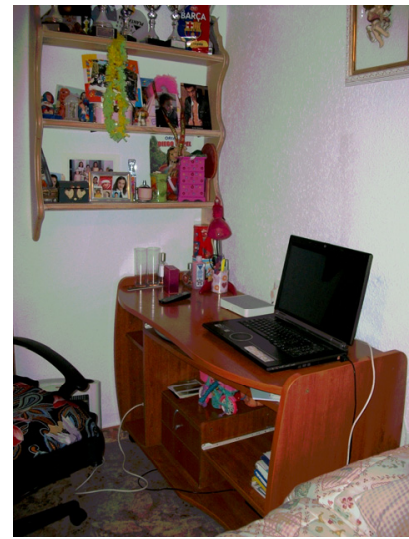

(Mesa de trabajo, alumna $3^{\circ}$ ESO)

No obstante, la habitación es adecuada en relación al espacio, luz, ventilación y ordenación de materiales, mostrando independencia del resto de habitaciones y privacidad para un uso potencialmente adecuado del tiempo de trabajo/ocio. 
Se confirma que la madre no ejerce ningún control sobre el tipo de páginas que visita su hija ni sobre la utilización que hace de las mismas, aunque declara que considera que lo utiliza tanto para las redes como para el estudio.

"No controla las páginas que visita o para qué utiliza el ordenador, aunque a veces veo que hace cosas de estudio. La verdad es que la mayoría de las veces está comunicándose con sus amigos en el tuenti, que es la página en que están y allí hace mucho de fotos o chat" (Madre)

La alumna reconoce que suele dedicar tres horas diarias a internet, si bien el periodo fijo es por la noche, antes de dormirse y defiende las redes sociales como la principal herramienta de uso recreativo y de comunicación.

"Sobre todo por la noche...De todas formas suelo coger una hora y medio por la tarde y luego por la noche otra hora y media Lo mejor son las redes sociales porque allí está todo junto. En el tuenti lo tienes todo..." (Alumna profundización).

\section{El sentido de las tecnologías en el siglo XXI}

En opinión del dinamizador, es un hecho que se está imponiendo la utilización de las tecnologías digitales en los jóvenes: móvil, internet, etc.

"Aquí con 9-10 años ya llevan móvil y eso es imposible pararlo" (Dinamizador).

En la misma línea aparecen los comentarios de los alumnos entrevistados, al señalar que "si desaparecieran estas tecnologías sería un descontrol, ya que... preferiría que desaparecieran otras cosas, y lo último el ordenador (otros amigos prefieren el móvil)" (Alumnos).

Reconocen saber que no es bueno estar muchas horas delante pero les gusta.

Echarían en falta el ordenador porque les hace falta el Msn y además declaran que tiene muchos programas y vale para muchas cosas. Les gusta más el Msn que la comunicación cara a cara porque no hace falta identificarse y pueden hacer lo que quieran, mandarse fotos, etc. Si fuera siempre con Webcam no les gustaría porque perdería la intimidad, "daría vergüenza lo que pudiera decir" (Alumnos).

Según declara el dinamizador, los móviles e internet tienen cosas buenas, podemos estar así en comunicación que es bueno y puedes tener rápida información que necesitas, considerando a internet como la enciclopedia más grande.

"Ventajas tiene muchas, porque tienen mucha información de primera mano, con un acceso muy directo. Los inconveniente, pues que lo utilizan más como juego que para buscar información" (Madre).

Por tanto, su utilización puede facilitar ampliamente el desarrollo del conocimiento. Lo negativo, en palabras del dinamizador, es cómo utilizar ese conocimiento, "el peligro es que los niños ya saben más que los padres y si antes les dábamos las pautas a los críos hoy los padres no tienen ese conocimiento e internet - móvil se les escapa" (Dinamizador). 
Sin embargo su uso y abuso puede conllevar problemas de diverso ámbito y consideración que exigen una orientación y educación por parte de las instancias educativas (familia y escuela) para impedir que los adolescentes conviertan lo que inicialmente es una ventaja del progreso en un obstáculo para su adecuado desarrollo social, afectivo y profesional.

"El problema es que te metes y se te olvida que tienes que estudiar" (Alumna profundización)

Los padres no saben lo que hacen los críos con ellos. Habrá quien los utilice con buenos fines y otros que no obtendrán recompensan o incluso perjuicios. Aquí se intenta promover un uso bueno de las NNTT, para que en su casa puedan trasladarlo, pero el dinamizador reconoce que no es fácil.

Advierte que no se educa en las escuelas en este sentido, además hablamos de una red mundial con intereses determinados y aunque se vea que tiene cosas buenas también hay riesgos y precisaría unidad, que no la hay, de todas las instancias. En su opinión, la información debería iniciarse en los padres de hijos pequeños ya que a los 5-6 años ya estarán manejando un ordenador, para que cuando llegue el momento estén preparados. Que los padres tengan claro lo que quieren para sus hijos y las consecuencias que tiene el uso de las NNTT, tanto lo bueno como lo malo. El problema es también el tiempo de los padres, además de su poca formación.

"No es tema de los padres. Es imposible, los padres no lo pueden controlar, si tú te quieres meter, te vas a meter, si no en tu casa, vas a Guadalinfo y te metes" (Alumna profundización).

El dinamizador advierte que hoy día internet está en todo lo que nos rodea y se puede aprender todo y los docentes tampoco lo utilizan en modo educativo ni están actualizados al respecto, volcándose su uso como algo liviano, sin sacarle el partido que pudiera.

"Hoy las NNTT están ahí y se van a trabajar todas las materias con el ordenador, y más en el futuro, así que aparte de didáctica hay que saber utilizar esto" (Dinamizador).

A modo de conclusión, el dinamizador nos señala que a esto no se le pondrá nunca freno así que habrá que reorientar mediante la educación un buen uso y aprovechamiento. No hay que controlar sino educar antes de que lo use mal, desde pequeños. Todos aprendemos de nuestros errores y uso y lo que necesitamos es que nos orienten, no que nos controlen. 


\section{4. conclusiones}

Es un hecho constatable que se hace imprescindible ampliar los usos de internet que ahora hacen los adolescentes, para lo cual sería necesario guiarlos, abrirles nuevas opciones y formas de construir su conocimiento. Pero para conseguir todo esto no sólo hace falta facilitar el acceso y formación de estos medios con centros como los que se abordan en este estudio, sino que se vuelve igualmente necesario trabajar un entramado social complejo que pasaría por reestructurar las funciones de la familia y de la escuela, y por supuesto poner los medios necesarios para que estas reestructuraciones fueran posibles.

Así, estos medios no son únicamente posibilitar el acceso a un ordenador conectado a internet; éste sería el último eslabón de la cadena. El primero debería implicar el diseño de una buena política de protección y formación a la familia que se planteara adoptar las medidas necesarias respecto a los horarios laborales, que diera a los padres la posibilidad de acceder a una mejor formación cultural y también el tiempo necesario para poder ejercer como padres en su propio hogar. Es un dato importante comprobar la relación directa que existe entre la formación cultural de los padres y su tiempo de dedicación a los hijos, con el rendimiento escolar de éstos (Livingstone, 2001; Tapscott, 1998).

Esta relación se irá haciendo también cada vez más evidente en la forma en que distintas familias utilizan la red. Si no se ponen los medios necesarios, internet no hará más que aumentar los desniveles ya existentes en cuanto a acceso a la información y competencia escolar, que están marcados no sólo por el disponer o no de tecnologías de la comunicación en el hogar, sino también por el nivel de recursos materiales en general, su accesibilidad y el interés y apoyo familiar.

\section{Notas}

${ }^{1}$ Dicho estudio forma parte de un proyecto de excelencia de la Junta de Andalucía 2008 denominado ESCENARIOS, TECNOLOGÍAS DIGITALES Y JUVENTUD EN ANDALUCÍA, (con referencia: HUM-02599), dirigido por D. Félix Angulo Rasco, cuyo objetivo general se encuentra en comprender el acceso y uso de Internet de la juventud española, así como las interacciones y reestructuraciones que despliegan, desarrollan y generan en tres escenarios socio-educativos: Centros de Secundaria/Bachillerato, los hogares, las bibliotecas y los cibercafés/centros de ocio.

${ }^{2}$ Furlong (2002) utiliza la expresión 'screen-based technologies'. 


\section{Referencias bibliográficas}

Adell, J. (2003). Internet en el aula: a la caza del tesoro. Edutec. Revista Electrónica de Tecnología Educativa, $n^{\circ}$ 16, 13-34. Recuperado el 5 de abril, 2012 de http://www. uib.es/ depart/gte/edutec-e/revelec16/adell.htm.

Adell, J. (2004). Internet en el aula: las WebQuest. Edutec. Revista Electrónica de Tecnología Educativa, $n^{\circ}$ 17, 35-55. Recuperado el 6 de marzo, 2012, de http://edutec. rediris.es/Revelec2/revelec17/adell_16a.htm.

Albero, M. (2001). Internet, escuela y vida cotidiana en la infancia. Telos (Revista de Estudios Interdisciplinarios, vol. 3, $\mathrm{n}^{\circ}$ 1, 9-20.

Área, M. (1996). La tecnología educativa y el desarrollo e innovación del currículum. Recuperado el 12 de marzo, 2012, de http://www.ull.es/departamentos/didinv/ tecnologíaeducativa / doc-sep.htm.

Balanskat, A., Blamire, R. y Kefala, S. (2006). The ICT Impact Report. A review of studies of ICT impact on schools in Europe. European Schoolnet, European Comission. Recuperado el 18 enero, 2008, de http.//ec.europa.eu/education/doc/reports/doc/ ictimpact.pdf.

Bibeau,R. (1998). L’élève rapaillé. Les cahiers pedagogiques, 362, 20-23.

Buckingham, D. (1998). Teaching Popular culture. Beyond Radical Pedagogy. London: UCL Press.

Buckingham, D. y Sefton-Green, F. (1999). Children, Young People and Digital Technology (Special Issue). Convergence: The Journal of Research into New Media Technologies, winter, vol. 5 number 4, 13-29.

Castells, M. (2001). The Internet Galaxy. Reflections on Internet, Business and Society. Oxford: Oxford University Press.

Cabero, J. (1998). Corren nuevos tiempos para seguir pensando en nuevos proyectos. El papel de las nuevas tecnologías en el cambio y la innovación educativa: sus posibilidades y limitaciones. En M. Cebrián y otros (Coords.) Recursos tecnológicos para los procesos de enseñanza y aprendizaje. Málaga: ICE/Universidad de Málaga (pp. 126-133).

Claro, M. (2010). Impacto de las Tecnologías Digitales en el aprendizaje de estudiantes. Estado del Arte. Documento de Proyecto. Proyecto @LIS2, Componente Educación. Santiago de Chile: División de Desarrollo Social CEPAL.

Condie, R. y Munro, B. (2007). The impact of ICT in schools - a landscape review. Recuperado el 15 de enero, 2008, de http.//partners.becta.org.uk/uploaddir/downloads/ page_documents/research/impact_ict_schools.pdf

Cox, M. (2003). ICT and attainment: A review of the research literature. ICT in Schools Research and Evaluation Series - No.17. DfES-Becta. Recuperado el 21 de mayo, 2012, de www.becta.org.uk/page documents/research/ict attainment summary. pdf 
Cox, M. y Marshall, G. (2007). Effects of ICT: Do we know what we should know? Education and Information Technologies, 12(2), 59-70.

Cummis, J. (1989). De la ciudad aislada a la aldea global. El microordenador como catalizador del aprendizaje cooperativo y el intercambio cultural. Comunicación, lenguaje y educación, 1, 57-70.

Dias, L.B. (1999). Integrating Technology. Learning \& Leading with Technology, $n^{\circ} 27$ (3), 10-21.

Dodge, B. (2002). The WebQuest Page. Recuperado el 28 de febrero, 2012, de http://webquest.sdsu.edu.

Downes, S. (2004). Educational Blogging. Educause Review, vol. 39, $n^{\circ} 5$ (September/October 2004), 14-26. Recuperado el 5 de mayo, 2012 de http://www.educause.edu/pub/er/erm04/erm0450.asp.

Etcheverry, R.E. (2005). Internet y educación. Recuperado el 20 de abril, 2012, de http://www.marketingdireccion.com/descargas/Internet y Educacion.pdf.

Elboj, C., Valls, R. y Fort, M. (2000). Comunidades de aprendizaje. Una práctica educativa en la sociedad de la información. Cultura y educación, 17/18, 129-141.

Gauntlett, D. (2000). Web.Studies: Rewiring Media Studies For The Digital Age. London: Arnold

Goetz, J.P. y LeCompte, M.D. (1988). Etnografía y diseño cualitativo en investigación educativa. Madrid: Ediciones Morata, S.A.

Guardia, L. y Sangrá, A. (2002). Multimedia Instructional Design vs. Learning Objects Development. ON LINE EDUCA BERLIN, 2002. Recuperado el 20 de mayo, 2012, de http://www.online-educa.com/en/.

Harrison, C. y Lewin, C. (2001). The ImpaCT2 evaluation: attempting to evaluate the impact on school achievement of ICT in the schools, in the home, and in the community. Paper presented at CAL2001 conference, University of Warwick.

Holloway, S.L. y Valentine, G. (2003). Cyberkids: children in the information age. London: Routledge Falmer.

Howard, S. (1998). Wired-Up: Young People and the Electronic Media. London: UCL Press.

Hutchby, I. y Moran-Ellis, J. (2001). Children, Technology and Culture. The Impacts of Technololgies in Children's everyday Lives. London: Routledge Falmer.

Levin, H.M. (2000). Las Escuelas Aceleradas. Una década de evolución. PREAL,18,1-27. Recuperado el 21 de mayo de 2012, de http://www.preal.cl/doctra18.pdf.

Livingstone, S. (1998). Mediated Childhoods. A Comparative Approach to Young People's Changing Media Enviroment in Europe. European Journal of Communication, vol 13, number 4, 435-456. 
Livingstone, S. (2001). Children and their Changing Media Enviroment: A European Comparative Study. London: Lawrence Earlbaum Associates.

Livingstone, S. y Bovill, M. (1999). Jóvenes, Nuevos Medios: Informe del Proyecto de Investigación: Los niños, los jóvenes y el cambiante medio ambiente medios de comunicación. Londres: London School of Economics and Political Science.

Magrid, L.J. (1998). Child Safety on the Information Highway. Washington: National Center for Missing and Exploited Children.

Martínez, F. (2004). Alicia en el país de las tecnologías. En F. Martínez y M.P. Prendes;

Martínez, F. (2004). Alicia en el país de las tecnologías. En F. Martínez y Ma . P. Prendes (Coords.), Nuevas Tecnologías y Educación (pp. 195-214). Madrid: Pearson.

Martínez, F. y Solano, I.M. (2003). Redes para la formación. En F. Martínez (Comp.). Redes de comunicación en la enseñanza. Las nuevas perspectivas del trabajo cooperativo (pp. 31-63). Barcelona: Paidós.

Oswell, D. (1999). The Dark Side of Cyberspace. Internet Content Regulation and Child Protection. Convergence, vol. 5, number 4, 42-61.

Papert, S. (1995) La máquina de los niños. Replantearse la educación en la era de los ordenadores. Barcelona: Paidós.

Rodríguez, G., Gil, J. y García, E. (1999). Metodología de la investigación cualitativa. Málaga: Aljibe.

Stake, R. (1995). El arte de la investigación del caso. Thousand Oaks, C.A: Sage Publications.

Tapscott, D. (1998). Growing Up Digital. The Rise of the Net Generation. New York: Mc Graw Hill.

Taylor, S. J. y Bogdan, R. (1986). Introducción a los métodos cualitativos de investigación. La búsqueda de significados. Buenos Aires: Editorial Paidós.

Taylor, H. y Hogenbirk, P. (2001) Information and communication technologies in education. The School of the Future. Massachussets-USA: Kluwer Academic Publishers.

Vázquez, R. y Angulo, F. (2003). Introducción a los estudios de casos. Los primeros contactos con la investigación etnográfica. Málaga: Aljibe.

Vigo, M.B. (2004). Comunicación y cooperación, Tecnologías de la información y la comunicación en la enseñanza del lenguaje escrito. Necesidades en una escuela para la diversidad. En Actas II Congreso La Educación en Internet e Internet en la Educación (pp. 130-146). Madrid: Ministerio de Educación y Ciencia.

Walker, R. (1989). Métodos de investigación para el profesorado. Madrid: Morata 


\section{Nota biográfica}

Antonio Luque de la Rosa. Profesor Dr. en el Departamento de Didáctica y Organización Escolar de la Universidad de Almería, en la cual desempeña el cargo de Director del Secretariado de Orientación Educativa y Vocacional. Sus líneas de investigación se centran en la atención a la diversidad, la orientación educativa y la tecnología educacional, habiendo participado en múltiples proyectos internacionales sobre las citadas temáticas y con diversas publicaciones en la materia.

C/ Galán de Noche, 13, A4-3ºB. 04007 (Almería). aluque@ual.es 